\title{
Incorporating tumour pathology information into breast cancer risk prediction algorithms
}

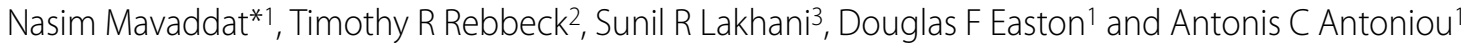

\begin{abstract}
Introduction: Mutations in BRCA1 and BRCA2 confer high risks of breast cancer and ovarian cancer. The risk prediction algorithm BOADICEA (Breast and Ovarian Analysis of Disease Incidence and Carrier Estimation Algorithm) may be used to compute the probabilities of carrying mutations in BRCA1 and BRCA2 and help to target mutation screening. Tumours from BRCA1 and BRCA2 mutation carriers display distinctive pathological features that could be used to better discriminate between BRCA1 mutation carriers, BRCA2 mutation carriers and noncarriers. In particular, oestrogen receptor (ER)-negative status, triple-negative (TN) status, and expression of basal markers are predictive of BRCA1 mutation carrier status.
\end{abstract}

Methods: We extended BOADICEA by treating breast cancer subtypes as distinct disease end points. Age-specific expression of phenotypic markers in a series of tumours from 182 BRCA1 mutation carriers, 62 BRCA2 mutation carriers and 109 controls from the Breast Cancer Linkage Consortium, and over 300,000 tumours from the general population obtained from the Surveillance Epidemiology, and End Results database, were used to calculate age-specific and genotype-specific incidences of each disease end point. The probability that an individual carries a BRCA1 or BRCA2 mutation given their family history and tumour marker status of family members was computed in sample pedigrees.

Results: The cumulative risk of ER-negative breast cancer by age 70 for BRCA1 mutation carriers was estimated to be $55 \%$ and the risk of ER-positive disease was 18\%. The corresponding risks for BRCA2 mutation carriers were $21 \%$ and $44 \%$ for ER-negative and ER-positive disease, respectively. The predicted BRCA1 carrier probabilities among ER-positive breast cancer cases were less than $1 \%$ at all ages. For women diagnosed with breast cancer below age 50 years, these probabilities rose to more than 5\% in ER-negative breast cancer, 7\% in TN disease and 24\% in TN breast cancer expressing both CK5/6 and CK14 cytokeratins. Large differences in mutation probabilities were observed by combining ER status and other informative markers with family history.

Conclusions: This approach combines both full pedigree and tumour subtype data to predict BRCA1/2 carrier probabilities. Prediction of BRCA1/2 carrier status, and hence selection of women for mutation screening, may be substantially improved by combining tumour pathology with family history of cancer.

\section{Introduction}

Genetic testing for $B R C A 1$ and $B R C A 2$ has important clinical implications: individuals found to carry mutations in these genes can be carefully monitored and receive preventive therapies including oophorectomy or mastectomy [1-6]. As genetic testing is expensive and may be associated with adverse psychological effects for

\footnotetext{
* Correspondence: nasim@srl.cam.ac.uk

${ }^{1}$ Centre for Cancer Genetic Epidemiology, Department of Public Health and Primary Care, University of Cambridge, Strangeways Research Laboratory, Worts Causeway, Cambridge CB1 8RN, UK

Full list of author information is available at the end of the article
}

the individual and their family, testing is only appropriate for those at highest risk of carrying mutations.

Several models have been developed for predicting risk of carrying BRCA1 or BRCA2 mutation and subsequently developing breast cancer [7]. These models generally include information on occurrence and age of diagnosis of breast cancer and other cancers in individuals and their families [7]. Breast tumours arising in carriers of $B R C A 1$ or BRCA2 mutations, however, also differ from one another and from sporadic tumours in terms of their pathological characteristics, including those assessed morphologically or by immunohistochemistry [8-12]. Incorporating information about the pathology of breast 
tumours in the proband or family members into risk-prediction algorithms may result in improved discrimination between BRCA1 mutation carriers, BRCA2 mutation carriers and nonmutation carriers, and provide a more accurate basis for identifying those individuals that may benefit from genetic testing.

Numerous studies have linked the absence of oestrogen receptor (ER) expression in breast tumours with $B R C A 1$ mutation carrier status using different laboratory methods, anti-ER antibodies, and cut-off points for ER staining [13-22]. In the largest study to date, the Breast Cancer Linkage Consortium (BCLC) reported that ER-negativity - defined by $<1 \%$ of breast cancer cells expressing detectable ER by immunohistochemistry - conferred an ageadjusted odds ratio of 13.98 (95\% confidence interval, 7.1 to $27.7 ; P<0.0001)$ for $B R C A 1$ mutation carrier status compared with controls unselected for family history (FH) [10]. Furthermore, the ER status was found to be the most significant risk factor in multiple regression analyses including other factors that are individually significant predictors of $B R C A 1$ status. These factors included progesterone receptor, human epidermal growth factor receptor 2 (HER2), mitotic count, lymphocyte infiltration, and continuous pushing margins [10].

The triple-negative (TN) tumours are negative for ER, progesterone receptor, and HER2, and they define a subset of ER-negative disease. Subsets of TN tumours also express high-molecular-weight cytokeratins (CKs) (for example, CK5/6 and CK14), also referred to as basal CKs. Expression of basal CKs in TN tumours has been shown to provide additional information predictive of $B R C A 1$ status [11]. The distribution of ER status in breast tumours and CK expression amongst TN tumours from BRCA2 mutation carriers appears to be similar to that in tumours from the population overall $[10,11]$. HER2-positive tumours have been shown less common in both $B R C A 1$ and $B R C A 2$ mutation carriers than in noncarriers [10].

We previously developed a risk-prediction algorithm for familial breast cancer and ovarian cancer - the Breast and Ovarian Analysis of Disease Incidence and Carrier Estimation Algorithm (BOADICEA) - which can be used to compute the probabilities of carrying BRCA1 and $B R C A 2$ mutations and the probabilities of developing breast cancer or ovarian cancer in the future [23]. BOADICEA models the effects of BRCA1 and BRCA2 mutations as well as a polygenic component representing the joint multiplicative effect of a large number of genes each of small effect [24,25]. BOADICEA has recently been extended to incorporate the associations between $B R C A 1$ and BRCA2 mutations and other cancer risks (such as prostate cancer, pancreatic cancer and male breast cancer) [23], and has been shown to discriminate well between mutation carriers and noncarriers in a large series of families identified through UK genetic clinics $[7,26]$. In the present report we propose a method for incorporating breast tumour pathology information into the BOADICEA risk-prediction model.

\section{Materials and methods \\ Age-specific distribution of ER status and distribution of other markers}

Data from the BCLC $[10,11]$ were used to obtain the agespecific proportions of ER-negative and ER-positive tumours, and the proportions of TN tumours and CK5/6expressing and/or CK14-expressing tumours for BRCA1 or $B R C A 2$ carriers or controls. Breast cancer patients with $B R C A 1$ and $B R C A 2$ mutations were identified through families with multiple relatives diagnosed with breast cancer or ovarian cancer. Data on 182 tumours in BRCA1 mutation carriers from 119 families, 62 tumours from $B R C A 2$ mutation carriers from 35 families, and 109 control women with breast cancer who were unselected for $\mathrm{FH}$ and not tested for mutation carrier status were available.

Details of the methods used to determine tumour marker expression are described by Lakhani and colleagues $[10,11]$. Briefly, assays were performed at a single, quality-assured laboratory, and both the proportion of tumour cells staining with ER, progesterone receptor, HER2, CK5/6 or CK14 antibodies and the intensity of staining as assayed by immunohistochemistry were recorded [10,11]. The present work had been carried out under local ethical approval. Owing to the sparse data on $B R C A 2$ tumours, and since the proportion of ER-positive tumours were not significantly different from that in controls [10], we assumed in the model that the age-specific proportions of ER-positive tumours and ER-negative tumours were the same as the proportions in the general population.

Age-specific proportions of ER-negative cancers and ER-positive cancers in the general population were obtained from the Surveillance Epidemiology, and End Results (SEER) database, a large population-based US breast cancer registry [27]. Data for the years 1990 to 2006 ( $n=326,839$ ) were used. Data were coded as ERpositive, ER-negative, or borderline. All analyses were restricted to females of white ethnicity with invasive breast cancer.

\section{Statistical methods \\ Extending BOADICEA to incorporate tumour pathology}

BOADICEA models the genetic susceptibility to breast cancer in terms of BRCA1, BRCA2 and a polygenic component representing the combined multiplicative effect of several loci, each of small effect [23]. 
The breast cancer incidence for individual $i$ is assumed to depend on the underlying genotype through a model of the form:

$$
\lambda_{i}(t)=\lambda_{0}(t) \exp \left(G_{i}(t)+P_{i}(i)\right)
$$

where $\lambda_{0}(t)$ is the baseline incidence at age $t, G_{i}(t)$ is the log relative risk corresponding to the major genotype (that is, BRCA1 carrier, BRCA2 carrier or nonmutation carrier) at age $t$, and $P_{i}(t)$ is the age-dependent polygenic effect assumed to be normally distributed with mean zero and variance $\sigma^{2}(t)$. The polygenic component is approximated by the hypergeometric polygenic model [28].

The incidence of ovarian cancer is modelled in a similar manner, but without a polygenic component.

The probabilities of developing breast cancer and ovarian cancer are assumed to be independent, conditional on the underlying genetic effects. Cancer incidences in BOADICEA are calendar and cohort specific. The overall age-specific incidences, averaged over all major genotypes and polygenotypes, are constrained to agree with the population incidences for England and Wales [29-35]. The BOADICEA model is implemented in the pedigree analysis program MENDEL v3.3 [36]. Additional model description and the model parameter estimates can be found in our previous publication [23].

To incorporate tumour phenotypes, we considered breast cancer subtypes as different disease end points. For example, to incorporate the ER status, the total observed breast cancer incidence was assumed to be:

$$
\lambda(t)=\mu(t)+v(t)
$$

where $\mu(t)$ is the incidence of ER-positive disease and $v(t)$ is the incidence of ER-negative disease. We also assumed that the probabilities of developing ER-negative or ER-positive breast cancer are independent, conditional on the underlying genotype. We assumed that the polygenic component $P_{i}(t)$ was identical for both ER-negative and ER-positive disease (that is, represented by the same set of polygenes conferring the same relative risks), although in principle this assumption could be relaxed. The incidence for each individual $i$ at age $t$ therefore follows a model of the form:

$$
\lambda_{i}(t)=\left(\mu_{i}(t)+v_{i}(t)\right) \exp \left(P_{i}(t)\right)
$$

where $\mu_{i}(t)$ and $v_{i}(t)$ are the major genotype-specific incidences for ER-positive and ER-negative disease, respectively, for individual $i$.

Given the existing genotype-specific (BRCA1 carriers, $B R C A 2$ carriers, and noncarriers) incidences in BOADICEA and the age-specific distribution of ER status in breast tumours from the BCLC and SEER data, our aim was to derive separate genotype-specific incidences for ER-positive disease and ER-negative disease. These were obtained by constraining the overall BRCA1 and BRCA2 incidences over ER status and polygenic effects to equal the average breast cancer incidence for $B R C A 1$ and $B R C A 2$ mutation carriers, estimated previously in BOADICEA; and by constraining the overall incidence over ER status, major gene (BRCA1 carriers, $B R C A 2$ carriers and noncarriers) and polygenic effects to agree with the population breast cancer incidences. Separate genotypespecific incidences were derived for TN ER-negative disease and non-TN ER-negative disease as well as for CK5/ 6- and/or CK14-expressing and non-expressing TN tumours using a similar approach. Details of the method are provided in Additional file 1.

The derived incidences were used in the penetrance calculations whenever information on the relevant tumour marker status was available. For individuals with no marker status information, penetrance calculations use the total breast cancer incidences (as in the standard BOADICEA model implementation [23]). The genetic model is therefore fully specified by the $B R C A 1$ and $B R C A 2$ mutation frequencies, the polygenic variance and genotype-specific incidences for each type of disease.

\section{$B R C A 1$ and $B R C A 2$ mutation carrier probabilities}

The probability that an individual carries a $B R C A 1$ or $B R C A 2$ mutation given $\mathrm{FH}$ and marker status (for example, ER status), was computed as follows:

$$
P(B R C A j / F H, E R)=\frac{P(B R C A j, F H, E R)}{P(B R C A 1, F H, E R)+P(B R C A 2, F H, E R)+P(\text { non-carrier }, F H, E R)}
$$

where $P(B R C A j, F H, E R)$ is the probability of observing the family with the particular FH and ER status, and the proband carrying a $B R C A j$ mutation $(B R C A j=B R C A 1$ carrier, $B R C A 2$ carrier, or noncarrier). These correspond to pedigree likelihoods generated using the MENDEL program [36].

\section{Calculations for example pedigrees}

We investigated the effect of incorporating tumour phenotypic information on the mutation carrier probabilities using a variety of different scenarios. Carrier probabilities were calculated in simple pedigrees for scenarios where the marker status of tumours is unknown, or is known in one or more members of a family. For simplicity, we assumed that there was no follow-up after the age of diagnosis of cancer in each case.

\section{Results}

ER status of tumours from mutation carriers and unselected breast cancers in the general population

Age-specific proportions of ER-negative tumours in BRCA1 mutation carriers and BRCA2 mutation carriers derived from the BCLC dataset are presented in Table 1. These proportions were obtained for ER status defined as 
Table 1: Oestrogen receptor-negative tumours as a proportion of total tumours in $B R C A 1$ and $B R C A 2$ mutation carriers

\begin{tabular}{lllllll}
\hline Carrier & $<30$ years old & $\begin{array}{l}\mathbf{3 0} \text { to } 39 \text { years } \\
\text { old }\end{array}$ & $\begin{array}{l}\mathbf{4 0} \text { to } 49 \text { years } \\
\text { old }\end{array}$ & $\begin{array}{l}\mathbf{5 0} \text { to } 59 \text { years } \\
\text { old }\end{array}$ & $\begin{array}{l}\mathbf{6 0} \text { to } 69 \text { years } \\
\text { old }\end{array}$ & $>\mathbf{7 0}$ years old \\
\hline$B R C A 1$ & 0.93 & 0.91 & 0.86 & 0.89 & 0.83 & $0.83^{\mathrm{a}}$ \\
$B R C A 2^{\mathrm{a}}$ & 0.44 & 0.26 & 0.47 & 0.14 & 0.20 & 0.15 \\
\hline
\end{tabular}

Data from the Breast Cancer Linkage Consortium (BCLC) [10]. aAs numbers were sparse, data were extrapolated from the nearest age group for BRCA1 carriers in updating the Breast and Ovarian Analysis of Disease Incidence and Carrier Estimation Algorithm, and population data were substituted for $B C L C$ data for $B R C A 2$ carriers.

positive where $>1 \%$ of cells stained with anti-ER antibody in immunohistochemistry assays. Similar results were obtained when a combination of the proportion of cells staining and a staining intensity equivalent to an Allred score of 2 - a score shown to correspond to clinical response to Tamoxifen [37-39] - was used (data not shown). Data for age categories $>70$ years were sparse for $B R C A 1$ carriers, and we extrapolated data from the age category 60 to 69 years for this group. Data for BRCA2 carriers were sparse in all age groups, resulting in jumps in proportions between adjacent intervals (Table 1). We therefore used population data [27] for $B R C A 2$ carriers in our analyses, as $B R C A 2$ carriers have been shown to have similar ER status distribution to unselected controls [10].

The age-specific proportions of ER-negative invasive breast cancers from white females in the general population obtained from the SEER database are shown in Figure 1. As previously reported, the proportion of ERnegative tumours decreases with age [40].

\section{Expression of other markers in tumours from mutation carriers and unselected controls}

The proportions of TN tumours amongst ER-negative tumours and of CK-expressing tumours among TN tumours derived from the BCLC dataset are presented in Table 2. These proportions were obtained for progesterone receptor, CK5/6 or CK14 - defined as positive when $>1 \%$ of cells stained with the specific antibodies in immunohistochemistry - and for HER2, where the majority of cells showed a strong complete membrane staining (equivalent to score 3 on the DAKO scoring system) $[10,11]$. Owing to sparse data, we used a constant proportion for expression of these tumour markers across all ages at diagnosis of breast cancer. As CK expression among TN tumours in BRCA2 carriers was similar to the distribution among TN tumours in breast cases unselected for $\mathrm{FH}$ and not tested for mutation $(P>0.05)$, we used data from these controls for $B R C A 2$ carriers in our analyses.

\section{Breast cancer subtype-specific risks}

ER-specific incidences were calculated for each of the five birth cohorts considered in BOADICEA. The resulting incidences (averaged over all polygenotypes) of ER-positive and ER-negative breast cancers in $B R C A 1$ carriers, $B R C A 2$ carriers and noncarriers for women born after 1950 are shown in Figure 2. The breast cancer incidence curve in BRCA1 mutation carriers follows closely the shape of the incidence curve for ER-negative disease (Figure 2a). This increases rapidly with age until about age 50 years but decreases gradually after this age. This pattern is similar to the incidence of ER-negative disease in noncarriers (Figure 2c). In contrast, the shape of the overall breast cancer incidence curve in BRCA2 mutation carriers is similar to that for ER-positive disease, where incidence increases with age, with an inflexion at about age 50 years (Figures $2 \mathrm{~b}$ ). This is also consistent with the agespecific pattern of ER-positive disease in noncarriers (Figure 2c) and in unselected controls [40].

Figure 3 shows the corresponding average cumulative risks of developing ER-positive and ER-negative breast cancer by genotype. The probabilities of developing ERpositive and ER-negative breast cancer for BRCA1 mutation carriers by age 70 were calculated to be $18 \%$ and $55 \%$, respectively. The corresponding risks for $B R C A 2$ mutation carriers were $44 \%$ and $21 \%$ for ER-positive disease and ER-negative disease, respectively. Subtype-specific incidences for TN tumours and basal CK-expressing or non-expressing TN tumours, and the corresponding average cumulative risks of developing these tumours, are provided in Additional file 2 (Supplementary figures S1 to S6).

\section{Prediction of BRCA1 and BRCA 2 carrier probabilities}

Figure 4 shows the predicted $B R C A 1$ and $B R C A 2$ carrier probabilities for an individual, ignoring $\mathrm{FH}$ information. Compared with the risks when the ER status of the tumour is unknown, the $B R C A 1$ carrier probabilities are higher at all ages when the tumour is known to be ERnegative, and are lower when the tumour is known to be ER-positive (Figure 4a). For example, for a breast cancer diagnosed at age 30 , the carrier probability is estimated to be 0.05 when the ER status is unknown, 0.11 when the tumour is ER-negative and 0.01 when the tumour is ERpositive. 


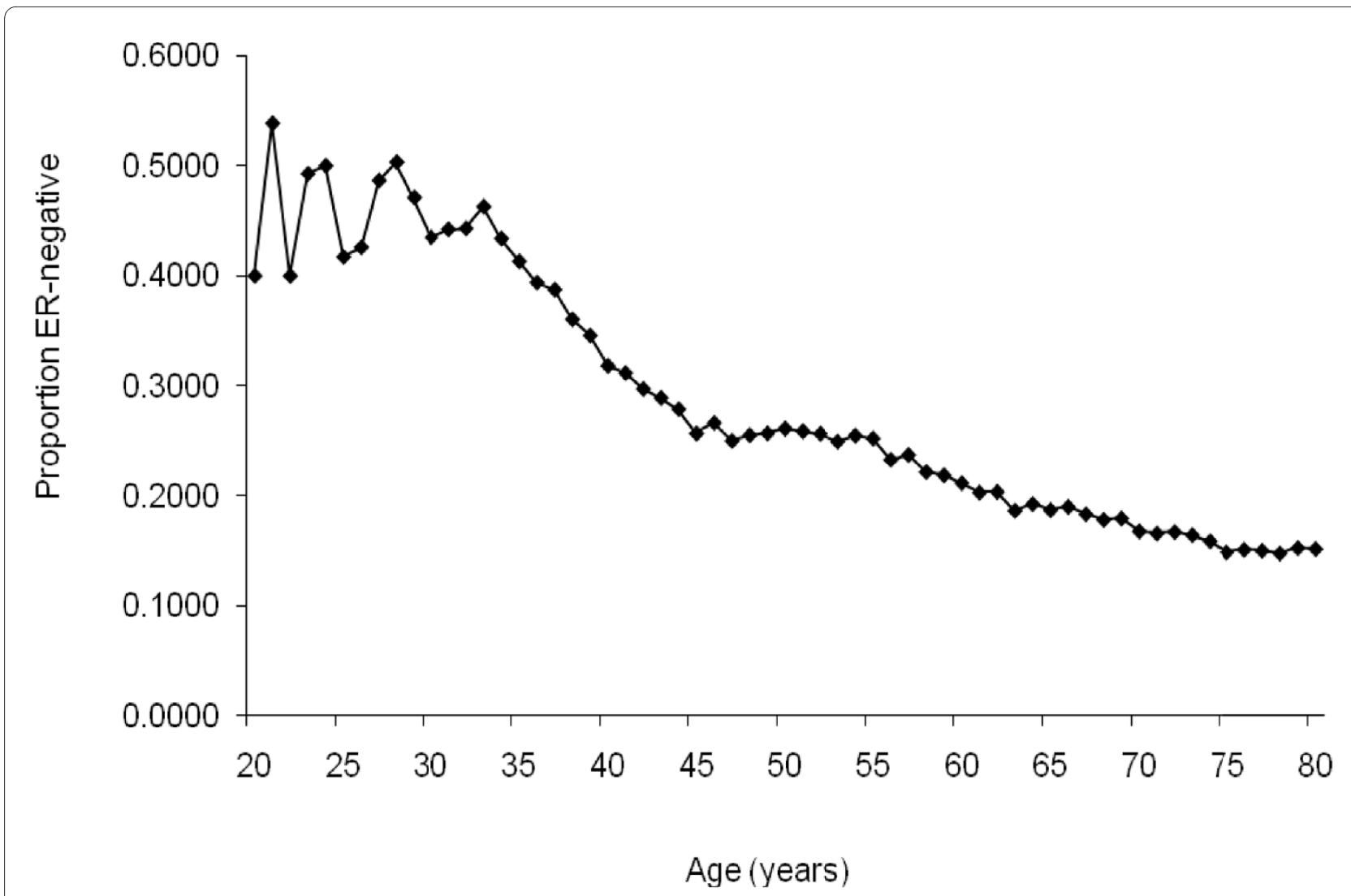

Figure 1 Proportion of oestrogen receptor-negative tumours from the general population. Oestrogen receptor (ER)-negative tumours as a proportion of all invasive breast cancers tested for ER expression in unselected females from the general population. Data from the Surveillance Epidemiology, and End Results database 1990 to 2006 [27].

Knowledge of the TN status and basal marker expression further influences mutation carrier probabilities (Figure $4 \mathrm{~b}$ to $4 \mathrm{~d}$ ). For example, for breast cancer diagnosed at age 30 , the BRCA1 carrier probability is estimated to be 0.19 when the tumour is TN and 0.02 when the tumour is ER-negative but not TN (Figure 4b). If both basal markers CK5/6 and CK14 are expressed on a TN tumour, the probability of carrying a BRCA1 mutation is
0.64 (Figure 4c). If neither $\mathrm{CK}$ is expressed on a $\mathrm{TN}$ tumour when both have been tested for, however, the carrier probability is 0.04 . Carrier probabilities for the scenario where a test is available only for CK5/6 are also shown (Figure 4c). Carrier probabilities for CK14-positive and CK14-negative tumours when a test is available only for CK14 were almost identical to those obtained when a test was available only for CK5/6 (data not

Table 2: Proportion of each tumour subtype in BRCA1 and BRCA2 mutation carriers and unselected controls

\begin{tabular}{|c|c|c|c|}
\hline Tumour phenotype & Controlsa & BRCA1 carriers & BRCA2 carriers \\
\hline TN (among ER-negative cases) & 0.53 & 0.90 & 0.86 \\
\hline CK5/6-expressing and CK14-expressing TNb,c & 0.14 & 0.49 & $0.38^{d}$ \\
\hline Either CK5/6-expressing or CK14-expressing $\mathrm{TN}$ b, c & 0.24 & 0.30 & $0.13^{d}$ \\
\hline CK5/6-expressing $\mathrm{TN}^{\mathrm{b}}$ (only $\mathrm{CK} 5 / 6$ tested) & 0.26 & 0.64 & $0.38^{d}$ \\
\hline CK14-expressing $\mathrm{TN}^{\mathrm{b}}$ (only CK14 tested) & 0.27 & 0.63 & 0.50 \\
\hline
\end{tabular}

Data from Breast Cancer Linkage Consortium [11]. CK, cytokeratin; ER, oestrogen receptor; TN, triple negative. aControls were breast cancer cases unselected for family history and untested for mutation. ${ }^{b}$ As a proportion of all TN tumours. ${ }^{\circ B}$ oth the CK5/6 status and the CK14 status have been tested. ${ }^{\mathrm{d} A s}$ numbers were sparse, proportions from controls were used in updating the Breast and Ovarian Analysis of Disease Incidence and Carrier Estimation Algorithm. 
(a)

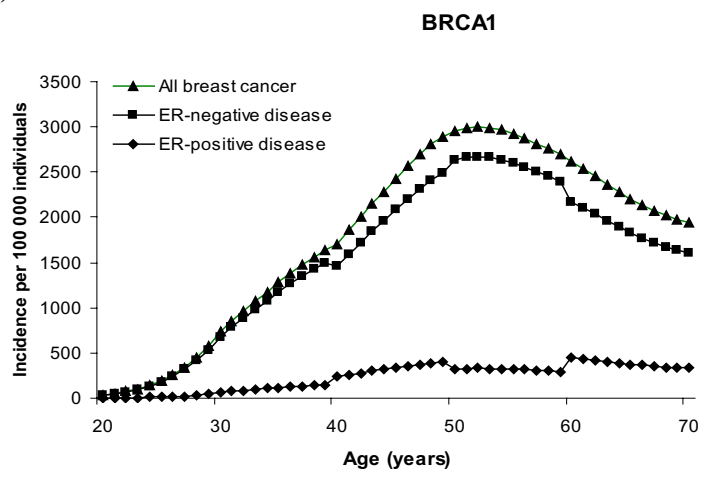

(b)

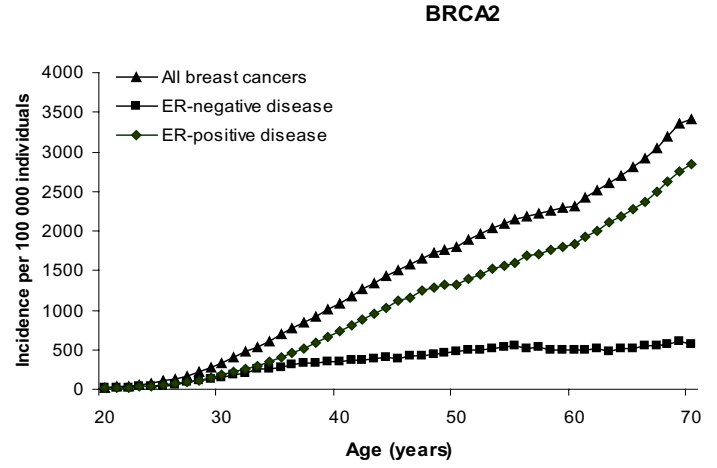

(c)

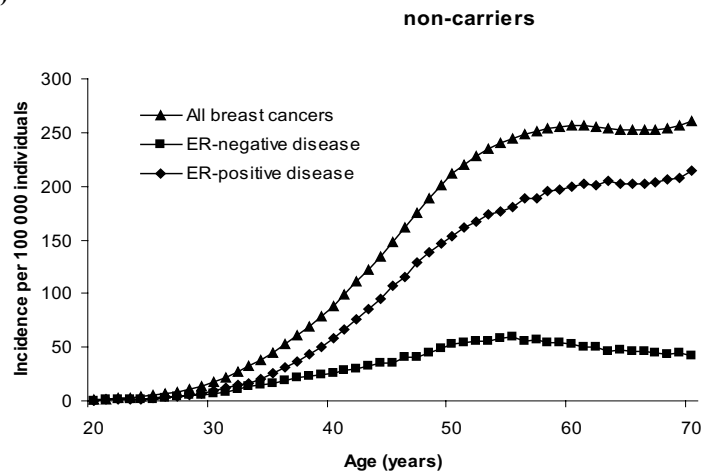

Figure 2 Incidence rates of oestrogen receptor-negative disease, oestrogen receptor-positive disease and all breast cancers. Incidence rates per 100,000 individuals of oestrogen receptor (ER)-negative disease, ER-positive disease and all breast cancers in (a) BRCA1 carriers, (b) BRCA2 carriers and (c) noncarriers, corresponding to women born after 1950 .

shown). The TN mutation status also influences $B R C A 2$ mutation carrier probabilities (Figure 4d).

We also estimated carrier probabilities considering both tumour markers and FH. Table 3 and Additional file 2 (Supplementary tables S1 and S2) show mutation carrier probabilities in a simple family with an affected mother and an affected (proband) daughter. Knowledge of the ER status of either tumour substantially influences the mutation carrier probabilities. Notably, the later the (a)

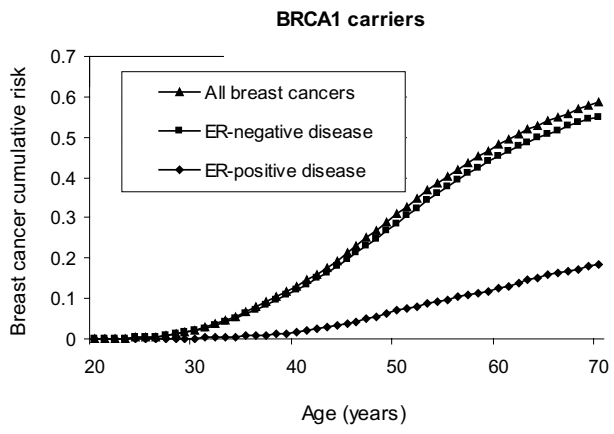

(b)

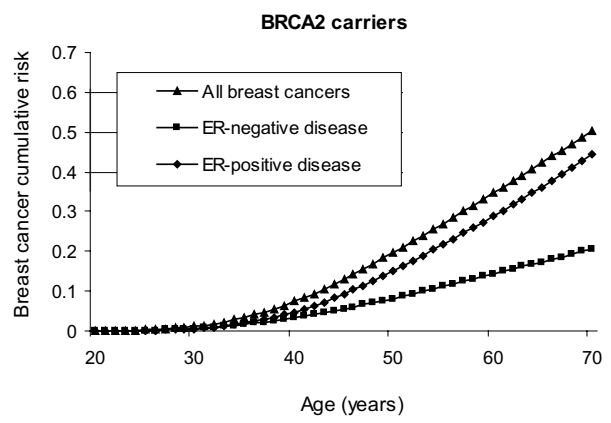

(c)

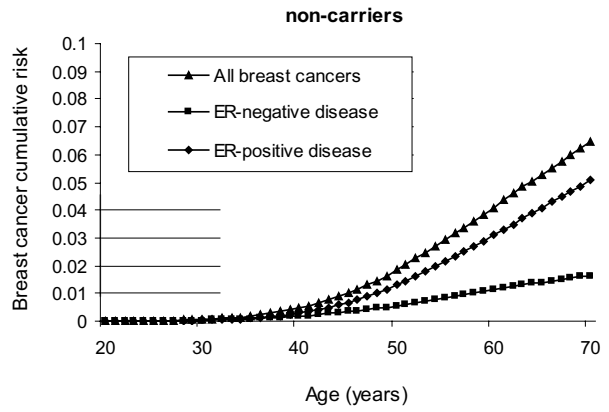

Figure 3 Average cumulative risk for oestrogen receptor-negative disease, oestrogen receptor-positive disease and all breast cancers. Average cumulative risk for oestrogen receptor (ER)-negative disease, ER-positive disease and all breast cancers in (a) BRCA1 carriers, (b) BRCA2 carriers, and (c) noncarriers, corresponding to women born after 1950.

age at breast cancer diagnosis, the greater the relative change in the BRCA1 mutation carrier probability. For example, if the mother is 70 years old when diagnosed with breast cancer, there is a threefold increase in mutation carrier probability when the tumour is ER-negative relative to when the ER status of the tumour is unknown. If the mother is 40 years old when diagnosed, the increase is less than twofold. In some cases, carrier mutation probabilities for $B R C A 2$ are also altered when information on 
(a)

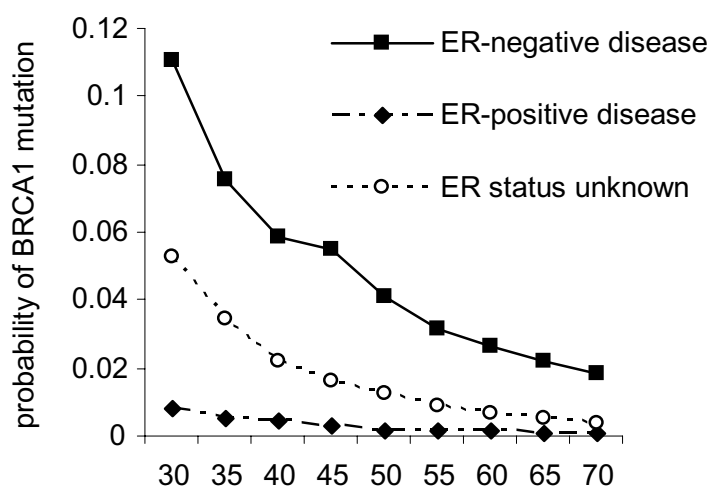

Age (years) (b)

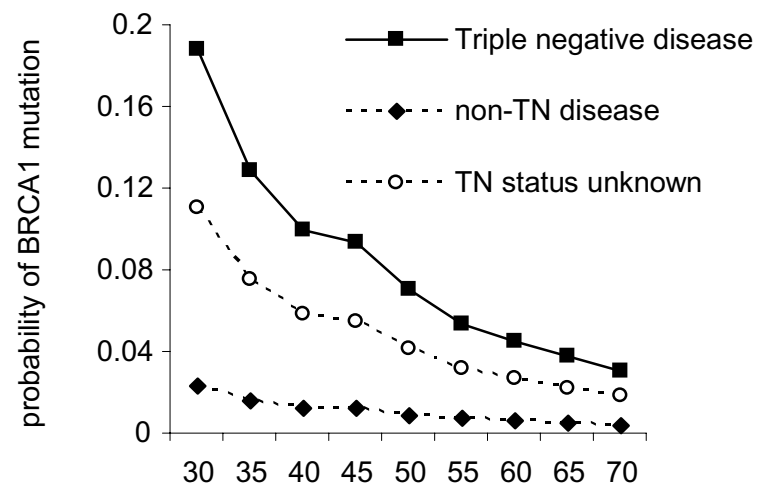

Age (years) (c)

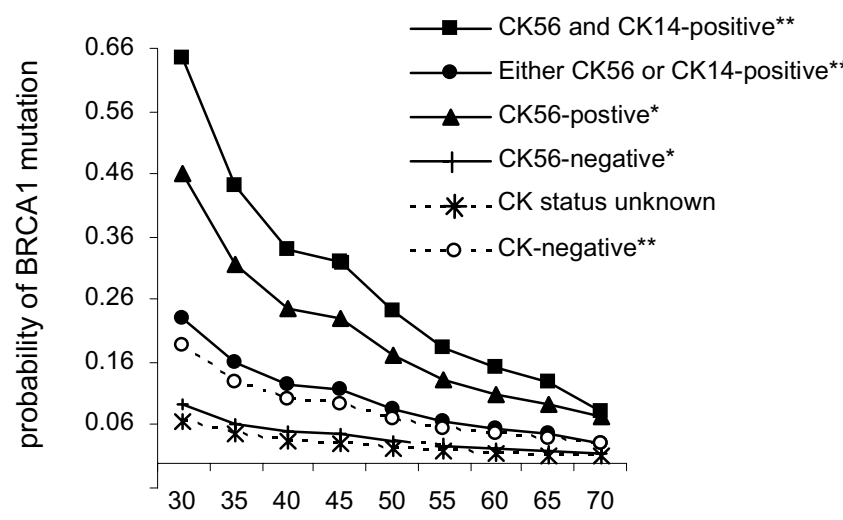

Age (years) (d)

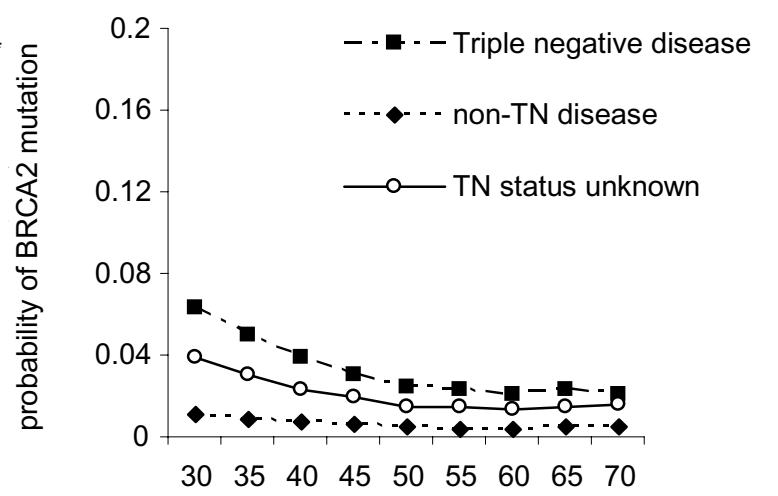

Age (years)

Figure 4 Influence of tumour pathology on mutation carrier probabilities for a single affected individual. Mutation carrier probabilities for a single affected individual with no knowledge of family history of breast cancer: BRCA1 carrier probabilities are shown in relation to (a) oestrogen receptor (ER) status, (b) tumour-negative (TN) status, when the tumour is known to be ER-negative, and (c) cytokeratin (CK)5/6 and/or CK14 expression when the tumour is known to be TN. In (c) scenarios where both basal markers have been tested $\left(^{* *}\right)$ or where only CK5/6 has been tested $(*)$ are shown. BRCA2 carrier probabilities are shown in relation to (d) TN status when the tumour is known to be ER-negative.

pathology of the tumour is available, because the $B R C A 1$ and $B R C A 2$ carrier probabilities are interdependent.

Figure 5 shows mutation carrier probabilities for a hypothetical pedigree in which sequentially more pathological information is available for a family member. Mutation carrier probabilities are influenced by additional information. For example, if the tumour is TN, the probability of carrying a $B R C A 1$ mutation is increased. If the tumour is ER-negative but not $\mathrm{TN}$, however, the probability of carrying a $B R C A 1$ mutation is even less relative to when the tumour is ER-negative but of unknown TN status.

Mutation screening for BRCA1 and BRCA2 is not $100 \%$ sensitive and can vary depending on the mutation screen- ing methods used. BOADICEA takes into account the reduced sensitivity of mutation testing (assumed to be $70 \%$ for $B R C A 1$ and $80 \%$ for $B R C A 2$ for the purposes of the example [23]). Figure 6 shows a pedigree in which the proband had been tested for mutations in BRCA1 or $B R C A 2$. As expected, the residual probability of carrying a $B R C A 1$ mutation is markedly higher if the tumour in either the proband or the mother is known to be ER-negative.

\section{Discussion}

We extended the BOADICEA model of genetic susceptibility to breast cancer and ovarian cancer to incorporate breast tumour pathology information - in particular, ER 
Table 3: Carrier mutation probabilities when the ER status of the mother is unknown, negative or positive

\begin{tabular}{|c|c|c|c|c|c|c|c|c|c|c|c|}
\hline \multirow{3}{*}{$\begin{array}{l}\text { Proband } \\
\text { age at } \\
\text { diagnosis }\end{array}$} & \multirow{3}{*}{$\begin{array}{l}\text { Mother's ER } \\
\text { status }\end{array}$} & \multicolumn{10}{|c|}{ Mother's age at diagnosis } \\
\hline & & \multicolumn{2}{|c|}{30 years } & \multicolumn{2}{|c|}{40 years } & \multicolumn{2}{|c|}{50 years } & \multicolumn{2}{|c|}{60 years } & \multicolumn{2}{|c|}{70 years } \\
\hline & & BRCA 1 & BRCA2 & BRCA1 & BRCA2 & BRCA1 & BRCA2 & BRCA1 & BRCA2 & BRCA1 & BRCA2 \\
\hline \multirow[t]{3}{*}{30 years } & Unknown & 0.45 & 0.16 & 0.24 & 0.14 & 0.15 & 0.10 & 0.09 & 0.09 & 0.06 & 0.10 \\
\hline & ER-negative & 0.63 & 0.11 & 0.46 & 0.10 & 0.36 & 0.08 & 0.25 & 0.08 & 0.19 & 0.09 \\
\hline & ER-positive & 0.13 & 0.25 & 0.08 & 0.17 & 0.04 & 0.11 & 0.04 & 0.10 & 0.03 & 0.10 \\
\hline \multirow[t]{3}{*}{40 years } & Unknown & 0.23 & 0.14 & 0.11 & 0.10 & 0.07 & 0.07 & 0.04 & 0.06 & 0.03 & 0.07 \\
\hline & ER-negative & 0.38 & 0.11 & 0.24 & 0.08 & 0.18 & 0.06 & 0.12 & 0.05 & 0.09 & 0.06 \\
\hline & ER-positive & 0.05 & 0.16 & 0.03 & 0.10 & 0.02 & 0.07 & 0.02 & 0.06 & 0.01 & 0.07 \\
\hline \multirow[t]{3}{*}{50 years } & Unknown & 0.12 & 0.08 & 0.06 & 0.06 & 0.04 & 0.04 & 0.02 & 0.04 & 0.02 & 0.04 \\
\hline & ER-negative & 0.22 & 0.08 & 0.14 & 0.05 & 0.11 & 0.04 & 0.07 & 0.03 & 0.06 & 0.04 \\
\hline & ER-positive & 0.02 & 0.09 & 0.01 & 0.06 & 0.01 & 0.04 & 0.01 & 0.04 & 0.01 & 0.04 \\
\hline \multirow[t]{3}{*}{60 years } & Unknown & 0.06 & 0.07 & 0.03 & 0.04 & 0.02 & 0.03 & 0.01 & 0.03 & 0.01 & 0.04 \\
\hline & ER-negative & 0.11 & 0.06 & 0.07 & 0.04 & 0.06 & 0.03 & 0.04 & 0.03 & 0.03 & 0.04 \\
\hline & ER-positive & 0.01 & 0.07 & 0.01 & 0.05 & 0.00 & 0.03 & 0.00 & 0.03 & 0.00 & 0.04 \\
\hline \multirow[t]{3}{*}{70 years } & Unknown & 0.03 & 0.07 & 0.01 & 0.05 & 0.01 & 0.03 & 0.01 & 0.03 & 0.00 & 0.04 \\
\hline & ER-negative & 0.06 & 0.07 & 0.04 & 0.05 & 0.03 & 0.03 & 0.02 & 0.03 & 0.02 & 0.04 \\
\hline & ER-positive & 0.01 & 0.07 & 0.00 & 0.05 & 0.00 & 0.03 & 0.00 & 0.03 & 0.00 & 0.04 \\
\hline
\end{tabular}

Both mother and proband are affected and the age of diagnosis of cancer in each case is the same as the age of last follow-up. Figures in italics represent genotype-specific risk when the oestrogen (ER) status is unknown. Bold figures indicate genotype-specific risk $<10 \%$ when the ER status is unknown, but $>10 \%$ when the ER status is known.

status. We divided breast cancer into distinct disease end points and used data on the proportion of ER-negative and ER-positive tumours in BRCA1 and BRCA2 carriers and the general population to derive age-specific incidences of ER-negative and ER-positive disease. Information on the TN status and expression of basal markers on $\mathrm{TN}$ tumours was also included in the model. Incorporating information on tumour pathology influences the predicted probabilities of carrying a $B R C A 1$ or $B R C A 2$ mutation, in particular $B R C A 1$, and may therefore have implications for genetic testing and clinical decisionmaking. The methodology presented here can in principle be applied to incorporate information in risk models for other diseases where the disease can be divided into distinct phenotypes such as different tumour sites in colorectal cancer [41,42] or subphenotypes of Crohn's disease [43].

Data on the distribution of ER status for $B R C A 1$ or $B R C A 2$ breast cancer tumours were obtained from a study conducted by the BCLC [10]. The ER status was measured by immunohistochemistry in a single research laboratory. A potential concern is that this assay may not be representative of typical assessment of ER status conducted in routine practice. The overall proportion of ERpositive tumours in the control series of the BCLC study, albeit relatively small, was however similar to that in the SEER series, suggesting there is little relative bias in the prevalence of ER-positivity. In addition, the cases in the BCLC study were predominantly drawn from multiple breast cancer families and this might have influenced the ER status, although there is no evidence to support an association between ER status and FH [44]. The number of mutation carriers was also relatively small (182 BRCA1 mutation carriers and $64 B R C A 2$ mutation carriers). The age-specific proportions of ER prevalence are therefore somewhat imprecise. In the final analyses we based the BRCA2 estimates on the proportion of ER-positive and ER-negative tumours in the general population data, due to lack of precision in the age-specific estimates in the BCLC data. Data from larger studies, such the Consortium of Investigators of Modifiers of BRCA1/2 [45], may provide more precise estimates and improve the modelling of BRCA2 in the future. 
To derive ER disease-specific incidences for nonmutation carriers we used the general population data from the SEER database combined with the BCLC data on mutation carriers. Data on ER status in SEER were obtained from medical records. The ER status was recorded as either positive or negative without reference to how these definitions were derived. These data may, however, be more representative of clinical situations where laboratories differ in the sensitivity with which they measure ER expression and cut-off points and scoring systems for ER positivity vary. As age-specific data were used, variation in ER expression according to age at diagnosis in control tumours is captured in our model. The observed proportion of ER-negative tumours in BCLC data among unselected controls under age 70 were $33.5 \%$. The corresponding expected number of ER-negative tumours in the SEER database would be $35.9 \%$. Data on TN status and cytokeratin expression in the general population were not available in these larger datasets and were derived from unselected controls from the BCLC.

We derived genotype-specific incidences for developing different pathological subtypes of breast cancer using

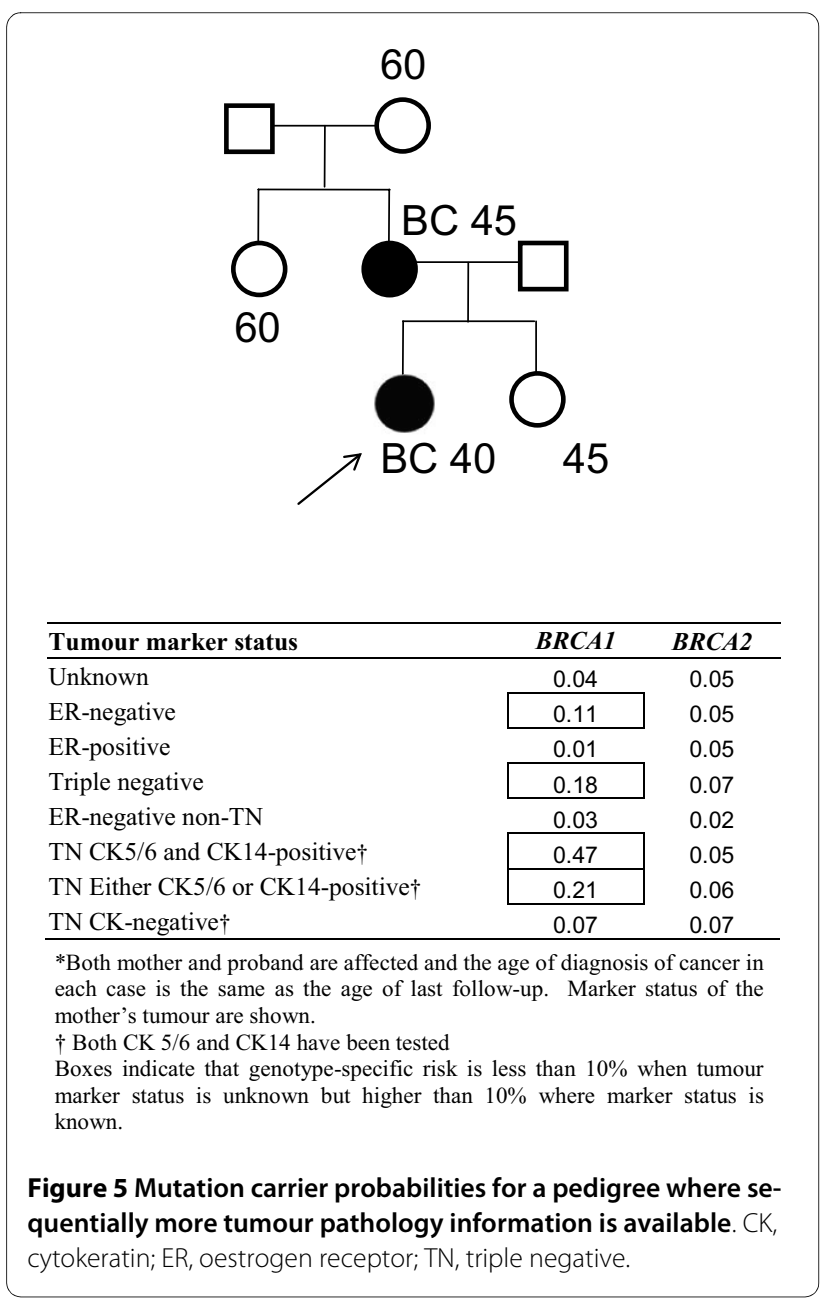

estimates of the genotypic relative risks, mutation frequencies in the general population, estimates of the polygenic distribution and the distributions of tumour pathology markers. For this purpose, we used estimates from published studies and registry data. Uncertainty surrounds each of these parameters, however, and a degree of measurement error may also be associated with the determination of pathological markers. Although in principle it may be possible to calculate confidence intervals for the derived disease-specific incidences or carrier probabilities, this would be complex due to the unknown correlation structure between the parameters entering the model. The derived incidences are therefore based on the best currently available estimates. The cumulative risks presented in Figure 3 do not take into account competing risks of dying from nonbreast cancer causes. These risks may therefore be somewhat higher than a woman would face in reality as they assume survival to the relevant age.

Our results show that incorporating tumour marker information into BOADICEA may result in the better discrimination between $B R C A 1$ carriers, BRCA2 carriers and nonmutation carriers. As expected, individuals with ER-negative tumours, or with ER-negative tumours diag-

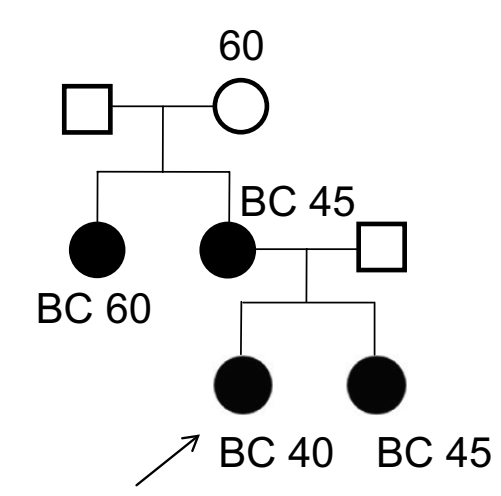

\begin{tabular}{|c|c|c|c|c|}
\hline \multirow[b]{2}{*}{ ER status } & \multicolumn{2}{|c|}{$\begin{array}{c}\text { Before } \\
\text { Mutation test }\end{array}$} & \multicolumn{2}{|c|}{$\begin{array}{l}\text { Mutation test } \\
\text { Negative* }\end{array}$} \\
\hline & BRCAI & BRCA2 & BRCA1 & BRCA2 \\
\hline Unknown & 0.16 & 0.21 & 0.07 & 0.06 \\
\hline Proband ER-negative & 0.35 & 0.17 & 0.17 & 0.05 \\
\hline Proband ER-positive & 0.04 & 0.24 & 0.01 & 0.06 \\
\hline Unknown & 0.16 & 0.21 & 0.07 & 0.06 \\
\hline Mother ER-negative & 0.38 & 0.16 & 0.18 & 0.05 \\
\hline Mother ER-positive & 0.05 & 0.24 & 0.02 & 0.06 \\
\hline
\end{tabular}

*sensitivity $70 \%$ for $B R C A 1$ and $80 \%$ for $B R C A 2$ mutations

Boxes indicate that genotype-specific risk is less than $10 \%$ when ER status is unknown but higher than $10 \%$ where ER status is known.

Figure 6 Influence of oestrogen receptor status on carrier probabilities when the proband tested negative for mutations. ER, oestrogen receptor. 
nosed in their family members, are predicted to have a higher BRCA1 mutation carrier probability. The current National Institute for Clinical Excellence guidelines recommend that an affected family member is screened for mutation if the predicted carrier probability for mutations in BRCA1 or BRCA2 combined is at least 20\% [46]. Knowledge of the ER status may therefore affect the decision to offer testing. For example, in a pedigree with an affected daughter and mother with ages of diagnosis at 40 and 50 years, respectively, the combined mutation carrier probabilities are 0.14 when the ER status is unknown but 0.24 if the mother's tumour is ER-negative. Similarly, the presence of an ER-positive tumour in the family may result in combined $B R C A 1$ and $B R C A 2$ carrier probabilities $<20 \%$.

Information on the $\mathrm{TN}$ status and expression of basal cytokeratins can further influence mutation carrier probabilities. In our example, the BRCA1 mutation carrier probability is increased over fourfold when the mother's tumour is ER-CK $14^{+} \mathrm{CK} 5 / 6^{+}$as compared with when it is ER-negative, but information on basal CK is unavailable. For a random 30-year-old breast cancer patient, the $B R C A 1$ mutation carrier probability is approximately 10 times greater for a patient with ER-CK $14^{+} \mathrm{CK} 5 / 6^{+}$versus ER-CK- breast tumour. Lakhani and colleagues argued previously that the use of CK in combination with ER status may provide a more specific test for $B R C A 1$ carrier status than ER alone, because ER-negative tumours are more frequently observed amongst control tumours than are basal CKs [11]. Our results further highlight the potentially important role of basal CKs in addition to ER status for risk prediction.

In the present model we assumed that the polygenic component is identical for both ER-negative and ER-positive disease and for tumours of other subtypes; that is, the polygenes confer the same relative risk by disease subtype. Studies that have evaluated the familial relative risks of breast cancer by the ER status of the proband have in general found no significant differences in the risks for ER-negative disease and ER-positive disease [47-54]. In addition, the segregation analysis of Antoniou and colleagues estimated similar polygenic variances of breast cancer risk for BRCA1 and BRCA2 mutation carriers [23]. Recent studies, however, have demonstrated that many of the common breast cancer susceptibility variants are associated more strongly with ER-positive disease [5558]. Further, Antoniou and colleagues have shown that modifying loci associated with $B R C A 2$ cancers, but not with $B R C A 1$ carriers, parallel those associated with ERpositive disease in the general population [55,59]. The polygenotypes for ER-positive and ER-negative thus cannot be perfectly correlated, but the extent of the correlation is not known. This may affect risk prediction in circumstances where the tumour subtype is available for more than one individual in a family. In principle, the methods we presented can be extended to allow for different polygenic components on ER-negative and ERpositive disease or other tumour subtypes once these can be estimated.

\section{Conclusions}

We have developed a method for incorporating tumour marker information into risk-prediction models by subdividing the overall disease into different disease end points and have implemented this method in BOADICEA to incorporate tumour ER status, TN status, and expression of basal markers. This will be implemented in the BOADICEA web interface for use in genetic counselling. The inclusion of phenotypic markers associated with $B R C A 1$ status should improve risk prediction in breast cancer.

\section{Additional material}

\begin{abstract}
Additional file 1 Extending BOADICEA to incorporate tumour pathology. Details of methods for extending BOADICEA to incorporate tumour pathology [60].

Additional file $\mathbf{2}$ Subtype-specific risks and carrier probabilities. Supplementary figure S1 shows the incidence rate of ER-negative, TN disease, and ER-negative non-TN disease: incidence rate per 100,000 individuals in (a) BRCA1 carriers, (b) BRCA2 carriers and (c) noncarriers, corresponding to women before after 1950. Supplementary figure $\$ 2$ shows average cumulative risk for ER-negative disease, TN disease and ER-negative non-TN disease: average cumulative risk for (A) BRCA1 carriers, (b) BRCA2 carriers and (c) noncarriers, corresponding to women born after 1950. Supplementary figure S3 shows the incidence rate of ER-negative, TN, CK-expressing and nonexpressing TN disease (both CKs tested): incidence rate per 100,000 individuals in (a) BRCA1 carriers, (b) BRCA2 carriers and (c) noncarriers, corresponding to women born after 1950. Supplementary figure S4 shows the average cumulative risk for ER-negative, TN and CK-expressing and non-expressing disease (both CKs tested): average cumulative risk for (a) BRCA1 carriers, (b) $B R C A 2$ carriers and (c) noncarriers, corresponding to women born after 1950. Supplementary figure S5 shows the incidence rate of ER-negative, TN, and CK5/6-expressing and non-expressing TN disease (only CK5/6 tested): incidence rate per 100,000 individuals in (a) BRCA1 carriers, (b) BRCA2 carriers and (c) noncarriers, corresponding to women before after 1950. Supplementary figure $\mathrm{S} 6$ shows the average cumulative risk for ER-negative, TN, and CK5/6-expressing and non-expressing TN disease (only CK5/6 tested) average cumulative risk for (a) BRCA1 carriers, (b) BRCA2 carriers and (c) non carriers, corresponding to women born after 1950. Supplementary table S1 shows carrier mutation probabilities when the ER status of the proband is unknown, negative or positive. Supplementary table $\$ 2$ shows carrier mutation probabilities when the ER status of the proband and the mother are unknown, negative or positive.
\end{abstract}

\section{Abbreviations}

BCLC: Breast Cancer Linkage Consortium; BOADICEA: Breast and Ovarian Analysis of Disease Incidence and Carrier Estimation Algorithm; CK: cytokeratin; ER: oestrogen receptor; FH: family history; HER2: human epidermal growth factor receptor 2; SEER: Surveillance Epidemiology; and End Results; TN: triple negative.

\section{Competing interests}

The authors declare that they have no competing interests.

\section{Authors' contributions}

NM, DFE and ACA contributed to the conception and execution of the project. NM carried out the analysis and wrote the manuscript. SRL was lead pathologist for the BCLC study. TRR contributed to discussions. ACA and DFE supervised the analysis and participated in writing the manuscript. 


\section{Acknowledgements}

The authors thank the BCLC for pathology data. NM was funded by a scholarship from the Medical Research Council. ACA is a Cancer Research-UK Senior Cancer Research Fellow. DFE is a CR-UK Principal Research Fellow.

\begin{abstract}
Author Details
${ }^{1}$ Centre for Cancer Genetic Epidemiology, Department of Public Health and Primary Care, University of Cambridge, Strangeways Research Laboratory, Worts Causeway, Cambridge CB1 8RN, UK, ${ }^{2}$ Center for Clinical Epidemiology and Biostatistics, Department of Biostatistics and Epidemiology, University of Pennsylvania, 217 Blockley Hall, 423 Guardian Drive, Philadelphia, PA 19104, USA and ${ }^{3}$ Molecular and Cellular Pathology, University of Queensland Centre for Clinical Research, Level 6 Building 71/918, University of Queensland, The Royal Brisbane \& Women's Hospital, Herston, 4029 Brisbane, Queensland, Australia
\end{abstract}

Received: 22 January 2010 Revised: 4 May 2010

Accepted: 18 May 2010 Published: 18 May 2010

\section{References}

1. Friebel TM, Domchek SM, Neuhausen SL, Wagner T, Evans DG, Isaacs $C$, Garber JE, Daly MB, Eeles R, Matloff E, Tomlinson G, Lynch HT, Tung N, Blum JL, Weitzel J, Rubinstein WS, Ganz PA, Couch F, Rebbeck TR: Bilateral prophylactic oophorectomy and bilateral prophylactic mastectomy in a prospective cohort of unaffected BRCA1 and BRCA2 mutation carriers. Clin Breast Cancer 2007, 7:875-882

2. Hartmann LC, Sellers TA, Schaid DJ, Frank TS, Soderberg CL, Sitta DL, Frost MH, Grant CS, Donohue JH, Woods JE, McDonnell SK, Vockley CW, Deffenbaugh A, Couch FJ, Jenkins RB: Efficacy of bilateral prophylactic mastectomy in BRCA1 and BRCA2 gene mutation carriers. J Nat/ Cancer Inst 2001, 93:1633-1637.

3. Meijers-Heijboer H, van Geel B, van Putten WL, Henzen-Logmans SC, Seynaeve C, Menke-Pluymers MB, Bartels CC, Verhoog LC, van den Ouweland AM, Niermeijer MF, Brekelmans CT, Klijn JG: Breast cancer after prophylactic bilateral mastectomy in women with a BRCA1 or BRCA2 mutation. N Engl J Med 2001, 345:159-164

4. Rebbeck TR, Lynch HT, Neuhausen SL, Narod SA, Van't Veer L, Garber JE, Evans G, Isaacs C, Daly MB, Matloff E, Olopade OI, Weber BL: Prophylactic oophorectomy in carriers of BRCA1 or BRCA2 mutations. N Engl J Med 2002, 346:1616-1622.

5. Rebbeck TR, Friebel T, Lynch HT, Neuhausen SL, van't Veer L, Garber JE, Evans GR, Narod SA, Isaacs C, Matloff E, Daly MB, Olopade OI, Weber BL: Bilateral prophylactic mastectomy reduces breast cancer risk in BRCA1 and BRCA2 mutation carriers: the PROSE Study Group. J Clin Oncol 2004, 22:1055-1062.

6. Rebbeck TR, Kauff ND, Domchek SM: Meta-analysis of risk reduction estimates associated with risk-reducing salpingo-oophorectomy in BRCA1 or BRCA2 mutation carriers. J Natl Cancer Inst 2009, 101:80-87.

7. Antoniou AC, Easton DF: Risk prediction models for familial breast cancer. Future Oncol 2006, 2:257-274.

8. Lakhani SR, Jacquemier J, Sloane JP, Gusterson BA, Anderson TJ, Van De Vijver MJ, Farid LM, Venter D, Antoniou A, Storfer-Isser A, Smyth E, Steel CM, Haites N, Scott RJ, Goldgar D, Neuhausen S, Daly PA, Ormiston W, McManus R, Scherneck S, Ponder BA, Ford D, Peto J, Stoppa-Lyonnet D, Bignon YJ, Struewing JP, Spurr NK, Bishop DT, Klijn JG, Devilee P, et al:: Multifactorial analysis of differences between sporadic breast cancers and cancers involving BRCA1 and BRCA2 mutations. J Nat/ Cancer Inst 1998, 90:1138-1145

9. Lakhani SR: The pathology of familial breast cancer: morphological aspects. Breast Cancer Res 1999, 1:31-35.

10. Lakhani SR, Van De Vijver MJ, Jacquemier J, Anderson TJ, Osin PP, McGuffog L, Easton DF: The pathology of familial breast cancer: predictive value of immunohistochemical markers estrogen receptor, progesterone receptor, HER-2, and p53 in patients with mutations in BRCA1 and BRCA2. J Clin Oncol 2002, 20:2310-2318.

11. Lakhani SR, Reis-Filho JS, Fulford L, Penault-Llorca F, van der Vijver M, Parry S, Bishop T, Benitez J, Rivas C, Bignon YJ, Chang-Claude J, Hamann U, Cornelisse CJ, Devilee P, Beckmann MW, Nestle-Kramling C, Daly PA, Haites N, Varley J, Lalloo F, Evans G, Maugard C, Meijers-Heijboer H, Klijn JG, Olah E, Gusterson BA, Pilotti S, Radice P, Scherneck S, Sobol H, et al: Prediction of BRCA1 status in patients with breast cancer using estrogen receptor and basal phenotype. Clin Cancer Res 2005, 11:5175-5180

12. Lynch BJ, Holden JA, Buys SS, Neuhausen SL, Gaffney DK: Pathobiologic characteristics of hereditary breast cancer. Hum Pathol 1998, 29:1140-1144

13. Cortesi L, Turchetti D, Bertoni C, Bellei R, Mangone L, Vinceti M, Federico $M$, Silingardi $V$, Ferrari S: Comparison between genotype and phenotype identifies a high-risk population carrying BRCA1 mutations. Genes Chromosomes Cancer 2000, 27:130-135.

14. Armes JE, Trute L, White D, Southey MC, Hammet F, Tesoriero A, Hutchins AM, Dite GS, McCredie MR, Giles GG, Hopper JL, Venter DJ: Distinct molecular pathogeneses of early-onset breast cancers in BRCA1 and BRCA2 mutation carriers: a population-based study. Cancer Res 1999, 59:2011-2017.

15. Foulkes WD, Metcalfe K, Sun P, Hanna WM, Lynch HT, Ghadirian P, Tung N, Olopade OI, Weber BL, McLennan J, Olivotto IA, Begin LR, Narod SA: Estrogen receptor status in BRCA1- and BRCA2-related breast cancer: the influence of age, grade, and histological type. Clin Cancer Res 2004, 10:2029-2034

16. Palacios J, Honrado E, Osorio A, Cazorla A, Sarrio D, Barroso A, Rodriquez S, Cigudosa JC, Diez O, Alonso C, Lerma E, Sanchez L, Rivas C, Benitez J: Immunohistochemical characteristics defined by tissue microarray of hereditary breast cancer not attributable to BRCA1 or BRCA2 mutations: differences from breast carcinomas arising in BRCA1 and BRCA2 mutation carriers. Clin Cancer Res 2003, 9:3606-3614.

17. Karp SE, Tonin PN, Begin LR, Martinez JJ, Zhang JC, Pollak MN, Foulkes WD: Influence of BRCA1 mutations on nuclear grade and estrogen receptor status of breast carcinoma in Ashkenazi Jewish women. Cancer 1997, 80:435-441.

18. Lidereau R, Eisinger F, Champeme MH, Nogues C, Bieche I, Birnbaum D, Pallud C, Jacquemier J, Sobol H: Major improvement in the efficacy of BRCA1 mutation screening using morphoclinical features of breast cancer. Cancer Res 2000, 60:1206-1210.

19. Eisinger F, Nogues C, Guinebretiere JM, Peyrat JP, Bardou VJ, Noguchi T, Vennin P, Sauvan R, Lidereau R, Birnbaum D, Jacquemier J, Sobol H: Novel indications for BRCA1 screening using individual clinical and morphological features. Int J Cancer 1999, 84:263-267.

20. Loman N, Johannsson O, Bendahl PO, Borg A, Ferno M, Olsson H: Steroid receptors in hereditary breast carcinomas associated with BRCA1 or BRCA2 mutations or unknown susceptibility genes. Cancer 1998, 83:310-319

21. Osin PP, Lakhani SR: The pathology of familial breast cancer: immunohistochemistry and molecular analysis. Breast Cancer Res 1999, $1: 36-40$.

22. Johannsson OT, Idvall I, Anderson C, Borg A, Barkardottir RB, Egilsson V Olsson $\mathrm{H}$ : Tumour biological features of BRCA1-induced breast and ovarian cancer. Eur J Cancer 1997, 33:362-371.

23. Antoniou AC, Cunningham AP, Peto J, Evans DG, Lalloo F, Narod SA, Risch HA, Eyfjord JE, Hopper JL, Southey MC, Olsson H, Johannsson O, Borg A, Pasini B, Radice P, Manoukian S, Eccles DM, Tang N, Olah E, Anton-Culver H, Warner E, Lubinski J, Gronwald J, Gorski B, Tryggvadottir L, Syrjakoski K, Kallioniemi OP, Eerola H, Nevanlinna H, Pharoah PD, et al.: The BOADICEA model of genetic susceptibility to breast and ovarian cancers: updates and extensions. Br J Cancer 2008, 98:1457-1466.

24. Antoniou AC, Pharoah PP, Smith P, Easton DF: The BOADICEA model of genetic susceptibility to breast and ovarian cancer. Br J Cancer 2004, 91:1580-1590

25. Antoniou AC, Easton DF: Models of genetic susceptibility to breast cancer. Oncogene 2006, 25:5898-5905.

26. Antoniou AC, Hardy R, Walker L, Evans DG, Shenton A, Eeles R, Shanley S, Pichert G, Izatt L, Rose S, Douglas F, Eccles D, Morrison PJ, Scott J, Zimmern RL, Easton DF, Pharoah PD: Predicting the likelihood of carrying a BRCA1 or BRCA2 mutation: validation of BOADICEA, BRCAPRO, IBIS, Myriad and the Manchester scoring system using data from UK genetics clinics. J Med Genet 2008, 45:425-431.

27. Surveillance, Epidemiology, and End Results (SEER) Program LimitedUse Data (1973-2006) [http://www.seer.cancer.gov]

28. Lange K: An approximate model of polygenic inheritance. Genetics 1997, 147:1423-1430.

29. Doll R, Payne P, Waterhouse AJ: Cancer Incidence in Five Continents Volume I. Berlin: Springer-Verlag; 1966. 
30. Doll R, Muir CS, Waterhouse AJ: Cancer Incidence in Five Continents Volume II. Geneva: UICC; 1970

31. Muir C, Waterhouse JAH, Mack TM, Powell J, Whelan S: Cancer Incidence in Five Continents Volume V. Lyon: IARC Scientific Publications; 1987.

32. Parkin DM, Muir CS, Whelan S, Gao YT, Ferlay J, Powell J: Cancer Incidence in Five Continents Volume VI. Lyon: IARC Scientific Publications; 1992.

33. Parkin DM, Whelan S, Ferlay J, Teppo L, Thomas DB: Cancer Incidence in Five Continents Volume VIII. Lyon: IARC Scientific Publications; 2002.

34. Waterhouse JAH, Muir C, Shanmugaratnam K, Powell J: Cancer Incidence in Five Continents Volume IV. Lyon: IARC Scientific Publications; 1982.

35. Waterhouse JAH, Muir C, Correa P, Powell J: Cancer Incidence in Five Continents Volume VIII. Lyon: IARC Scientific Publications; 1976.

36. Lange K, Weeks D, Boehnke M: Programs for pedigree analysis: MENDEL, FISHER, and dGENE. Genet Epidemiol 1988, 5:471-472.

37. Allred DC, Harvey JM, Berardo M, Clark GM: Prognostic and predictive factors in breast cancer by immunohistochemical analysis. Mod Pathol 1998, 11:155-168.

38. Gown AM: Current issues in ER and HER2 testing by IHC in breast cancer. Mod Pathol 2008, 21(Suppl 2):S8-S15.

39. Harvey JM, Clark GM, Osborne CK, Allred DC: Estrogen receptor status by immunohistochemistry is superior to the ligand-binding assay for predicting response to adjuvant endocrine therapy in breast cancer. $J$ Clin Oncol 1999, 17:1474-1481.

40. Anderson WF, Chatterjee N, Ershler WB, Brawley OW: Estrogen receptor breast cancer phenotypes in the Surveillance, Epidemiology, and End Results database. Breast Cancer Res Treat 2002, 76:27-36.

41. Gervaz P, Bouzourene H, Cerottini JP, Chaubert P, Benhattar J, Secic M, Wexner S, Givel JC, Belin B: Dukes B colorectal cancer: distinct genetic categories and clinical outcome based on proximal or distal tumor location. Dis Colon Rectum 2001, 44:364-372.

42. Azzoni C, Bottarelli L, Campanini N, Di CG, Bader G, Mazzeo A, Salvemini C, Morari S, Di MD, Donadei E, Roncoroni L, Bordi C, Sarli L: Distinct molecular patterns based on proximal and distal sporadic colorectal cancer: arguments for different mechanisms in the tumorigenesis. Int J Colorectal Dis 2007, 22:115-126.

43. Chapman JM, Onnie CM, Prescott NJ, Fisher SA, Mansfield JC, Mathew CG, Lewis CM, Verzilli CJ, Whittaker JC: Searching for genotype-phenotype structure: using hierarchical log-linear models in Crohn disease. Am J Hum Genet 2009, 84:178-187.

44. Althuis MD, Fergenbaum JH, Garcia-Closas M, Brinton LA, Madigan MP, Sherman ME: Etiology of hormone receptor-defined breast cancer: a systematic review of the literature. Cancer Epidemiol Biomarkers Prev 2004, 13:1558-1568

45. Chenevix-Trench G, Milne RL, Antoniou AC, Couch FJ, Easton DF, Goldgar $D E:$ An international initiative to identify genetic modifiers of cancer risk in BRCA1 and BRCA2 mutation carriers: the Consortium of Investigators of Modifiers of BRCA1 and BRCA2 (CIMBA). Breast Cancer Res 2007, 9:104

46. National Institute for Clinical Excellence: Clinical Guideline 14. Familial breast cancer: the classification and care of women at risk of familial breast cancer in primary, secondary and tertiary care. In Guidelines Manual London: NICE; 2004

47. Britton JA, Gammon MD, Schoenberg JB, Stanford JL, Coates RJ, Swanson CA, Potischman N, Malone KE, Brogan DJ, Daling JR, Brinton LA: Risk of breast cancer classified by joint estrogen receptor and progesterone receptor status among women 20-44 years of age. Am J Epidemiol 2002, 156:507-516.

48. Colditz GA, Rosner BA, Chen WY, Holmes MD, Hankinson SE: Risk factors for breast cancer according to estrogen and progesterone receptor status. J Nat/ Cancer Inst 2004, 96:218-228.

49. Cotterchio M, Kreiger N, Theis B, Sloan M, Bahl S: Hormonal factors and the risk of breast cancer according to estrogen- and progesteronereceptor subgroup. Cancer Epidemiol Biomarkers Prev 2003, 12:1053-1060

50. Huang WY, Newman B, Millikan RC, Schell MJ, Hulka BS, Moorman PG Hormone-related factors and risk of breast cancer in relation to estrogen receptor and progesterone receptor status. Am J Epidemiol 2000, 151:703-714.

51. Rosenberg LU, Einarsdottir K, Friman El, Wedren S, Dickman PW, Hall P, Magnusson C: Risk factors for hormone receptor-defined breast cancer in postmenopausal women. Cancer Epidemiol Biomarkers Prev 2006, $15: 2482-2488$
52. Rusiecki JA, Holford TR, Zahm SH, Zheng T: Breast cancer risk factors according to joint estrogen receptor and progesterone receptor status. Cancer Detect Prev 2005, 29:419-426.

53. Welsh ML, Buist DS, Aiello Bowles EJ, Anderson ML, Elmore JG, Li Cl: Population-based estimates of the relation between breast cancer risk, tumor subtype, and family history. Breast Cancer Res Treat 2009, 114:549-558.

54. Yang XR, Pfeiffer RM, Garcia-Closas M, Rimm DL, Lissowska J, Brinton LA, Peplonska B, Hewitt SM, Cartun RW, Mandich D, Sasano H, Evans DB, Sutter TR, Sherman ME: Hormonal markers in breast cancer: coexpression, relationship with pathologic characteristics, and risk factor associations in a population-based study. Cancer Res 2007, 67:10608-10617.

55. Garcia-Closas M, Hall P, Nevanlinna H, Pooley K, Morrison J, Richesson DA, Bojesen SE, Nordestgaard BG, Axelsson CK, Arias Jl, Milne RL, Ribas G, Gonzalez-Neira A, Benitez J, Zamora P, Brauch H, Justenhoven C, Hamann U, Ko YD, Bruening T, Haas S, Dork T, Schurmann P, Hillemanns P, Bogdanova N, Bremer M, Karstens JH, Fagerholm R, Aaltonen K, et al. Heterogeneity of breast cancer associations with five susceptibility loci by clinical and pathological characteristics. PLoS Genet 2008 4:e1000054

56. Garcia-Closas M, Chanock S: Genetic susceptibility loci for breast cancer by estrogen receptor status. Clin Cancer Res 2008, 14:8000-8009.

57. Stacey SN, Manolescu A, Sulem P, Rafnar T, Gudmundsson J, Gudjonsson SA, Masson G, Jakobsdottir M, Thorlacius S, Helgason A, Aben KK, Strobbe LJ, Albers-Akkers MT, Swinkels DW, Henderson BE, Kolonel LN, Le ML, Millastre E, Andres R, Godino J, Garcia-Prats MD, Polo E, Tres A, Mouy M, Saemundsdottir J, Backman VM, Gudmundsson L, Kristjansson K, Bergthorsson JT, Kostic J, et al: Common variants on chromosomes 2q35 and $16 q 12$ confer susceptibility to estrogen receptor-positive breast cancer. Nat Genet 2007, 39:865-869.

58. Stacey SN, Manolescu A, Sulem P, Thorlacius S, Gudjonsson SA, Jonsson GF, Jakobsdottir M, Bergthorsson JT, Gudmundsson J, Aben KK, Strobbe LJ, Swinkels DW, van Engelenburg KC, Henderson BE, Kolonel LN, Le ML, Millastre E, Andres R, Saez B, Lambea J, Godino J, Polo E, Tres A, Picelli S, Rantala J, Margolin S, Jonsson T, Sigurdsson H, Jonsdottir T, Hrafnkelsson J, et al: Common variants on chromosome $5 \mathrm{p} 12$ confer susceptibility to estrogen receptor-positive breast cancer. Nat Genet 2008, 40:703-706.

59. Antoniou AC, Spurdle AB, Sinilnikova OM, Healey S, Pooley KA, Schmutzler RK, Versmold B, Engel C, Meindl A, Arnold N, Hofmann W, Sutter C, Niederacher D, Deissler H, Caldes T, Kampjarvi K, Nevanlinna H, Simard J, Beesley J, Chen X, Neuhausen SL, Rebbeck TR, Wagner T, Lynch HT, Isaacs C, Weitzel J, Ganz PA, Daly MB, Tomlinson G, Olopade Ol, et al.: Common breast cancer-predisposition alleles are associated with breast cancer risk in BRCA1 and BRCA2 mutation carriers. Am J Hum Genet 2008, 82:937-948

60. Antoniou AC, Pharoah PD, McMullan G, Day NE, Ponder BA, Easton D: Evidence for further breast cancer susceptibility genes in addition to BRCA1 and BRCA2 in a population-based study. Genet Epidemiol 2001, 21:1-18.

\section{doi: $10.1186 / \mathrm{bcr} 2576$}

Cite this article as: Mavaddat et al., Incorporating tumour pathology information into breast cancer risk prediction algorithms Breast Cancer Research 2010, 12:R28 